Iberian Journal of the History of Economic Thought

ISSN-e 2386-5768

http://dx.doi.org/10.5209//JHE.58098

\title{
Entre textos y contextos
}

Estrella Trincado ${ }^{1}$

MONTES LIRA, LEONIDAS, Adam Smith en contexto. Una revaluación critica de algunos aspectos centrales de su pensamiento, Tecnos, Madrid, 2017, traducción de Sandra Cifuentes Dowling, 229 pp., ISBN. 978-84-309-7153-4

Esta es la traducción del inglés de un libro que marcó época en los estudios de Adam Smith. La primera versión, publicada en 2004 por Palgrave Macmillan, tuvo una recepción inesperada en la literatura. Leonidas Montes, profesor de la Universidad Adolfo Ibáñez de Chile y Doctor por la Universidad de Cambridge, reevaluaba la teoría de Adam Smith desde su contexto e influencias, desafiando las interpretaciones comúnmente aceptadas sobre el autor. En particular, destacaba la importancia del espectador imparcial y las virtudes de autocontrol y propiedad de las acciones en la teoría de Smith (self-command y propriety, dada su complejidad en la visión smithiana todavía sin traducir en el libro). La obra de Montes era fruto de la profunda reflexión de su tesis doctoral en Cambridge. Este camino reinterpretativo lo habían comenzado autores como Hont e Ignatieff (1983) y Donald Winch (1992), que ya apuntaron hacia la importancia del contexto. Enfatizaron que la Economía Política para Smith era una rama de la ciencia del legislador en el sentido antiguo del término, lo que le relacionaba con la labor de campaña por las virtudes públicas entre las que estaban la sabiduría y la prudencia. Haakonssen (1996) vinculaba esa tradición con la teoría de la ley natural y Charles Griswold (1999) intentaba completar la obra de Jurisprudencia que Smith había dejado incompleta. Igualmente, Vivienne Brown (1994), Fleischacker (1999), Emma Rothschild (2001) y Gloria Vivenza (2002), y después Jerry Evensky (2005), y otros, son excelentes e ineludibles textos que enmarcan a Adam Smith en la Ilustración escocesa. El tema, sin duda, parece de largo recorrido en un mundo en que virtudes como la prudencia y autocontrol tienen el alto valor que les da su escasez.

Así, Montes deliberadamente sigue la estela de Quentin Skinner (2002), que mostraba la importancia del contexto histórico: como dice Montes, podemos considerar la figura de Maquiavelo como "maestro del mal" pero no es posible comprender su figura sin considerar las circunstancias de su vida como servidor público, los acontecimientos políticos de Florencia y Europa en esos años, sus obras completas además de El Príncipe, y la influencia de los autores clásicos. Según el profesor Montes, el texto, el contexto y el lenguaje desempeñan un rol fundamental para comprender la historia de las ideas: qué se dice, porqué se dice y cómo se dice. Igual sucede con Adam Smith. En este sentido, Leonidas Montes se toma muy en serio el famoso Das Adam Smith Problem y analiza cómo surge el debate en la Alemania del siglo XIX, en el momento de eclosión de la Escuela Histórica de Economía alemana. Allí la búsqueda de identidad se combinó con un fuerte nacionalismo que en ocasiones se acercó al chauvinismo, con ciertos matices racistas. La reacción contra las ideas y políticas inglesas cosmopolitas llevó a los alemanes a caricaturizarle como un defensor del egoísmo. Según ellos, Smith había cambiado sus ideas iniciales idealistas tras su residencia en Francia donde estableció estrechas relaciones con el materialismo, de modo que estando "tan en boga en territorio galo por aquel entonces, regresó a Inglaterra convertido en materialista" (p. 51). Müller, List, Hildebrand criticaron la "parcialidad" de Smith así como su

Universidad Complutense de Madrid

estrinaz@ccee.ucm.es

https://orcid.org/0000-0002-3422-2360 
"cosmopolitanismo abstracto" considerando que Smith intentaba monopolizar la actividad productiva para Inglaterra. Las reacciones iniciales en Inglaterra, por ejemplo de Sir Leslie Stephen, no hicieron si no ahondar en la idea de que la Teoría de los Sentimientos Morales era superficial y que además era inconsistente con la Riqueza de las Naciones.

Según Montes el Das Adam Smith Problem no ha sido del todo superado, pero el autor demuestra Smith tampoco cambió sus ideas, y que no era ni un idealista ni un materialista. Leonidas Montes encuadra la visión de Smith dentro del humanismo de las virtudes cívicas y del realismo crítico. Según Montes, la simpatía y el auto-control son para Smith prerrequisitos del sentimiento moral y el desarrollo de otras virtudes. El autocontrol se relaciona con el control de las pasiones reverenciales y respetables, las virtudes de autogobierno. Pero el autocontrol smithiano no es una virtud estoica, si no socrática; no apela a la apatía, si no al poder interior.

También, la propiedad de las acciones es especialmente importante para Smith. Éste usa el término de propriety de diversas maneras. Una de ellas es cuando se refiere a él como la etapa que precede al logro de una concordancia de sentimientos, que es el requisito para alcanzar la simpatía mutua; otra es la vinculada a la virtud del autocontrol. Si las virtudes de la benevolencia, prudencia y justicia se juzgan por sus consecuencias, el espectador imparcial juzga directamente el autocontrol ya que esta virtud no depende de las consecuencias, sino de los motivos del agente. Por ello, Montes considera que Smith no era proto-utilitarista, si no que anticipa la ética kantiana. Y en esa labor de propaganda de las virtudes clásicas, Smith defiende, por ejemplo, que, aunque el ejército profesional tiene ventajas, la milicia tiene ciertos méritos morales. Pero, lo más importante, para defender esa idea Smith a menudo usa palabras cargadas de la tradición del humanismo cívico, como virilidad, cobardía o afeminado. Sin duda, Smith no era protoutilitarista, aunque no me resulta del todo convincente que fuera kantiano: aunque "la moral dentro de mí" de Kant se asemeja al espectador imparcial de Smith, el deber moral de Smith no depende de un imperativo categórico kantiano, ni de la razón, si no del sentimiento.

Finalmente, Montes analiza la influencia newtoniana en la metodología económica de Smith. Efectivamente, Montes cree que Smith era newtoniano, pero no como proponente de un método matemático-deductivo ni del equilibrio general walrasiano (idealista), sino porque, como Smith señalaba en sus Ensayos filosóficos, lo que él quería era desvelar la cadena de razonamientos para entender las verdaderas relaciones en los fenómenos naturales.

En fin, creo que este libro es de gran interés filosófico y por ello aplaudo la traducción del texto al español y animo a su lectura a todos los que quieran comprender el texto, el contexto y la intención de Adam Smith.

\section{Referencias}

Brown, Vivianne. 1994. Adam Smith's Discourse; Canonicity, Commerce and Conscience, London, Routledge.

Evensky, Jerry. 2005. Adam Smith's Moral Philosophy: A Historical and Contemporary Perspective on Markets, Law, Ethics and Culture, Cambridge: Cambridge University Press.

Fleischacker, Samuel. 1999. On Adam Smith's Wealth of Nations. A Philosophical Companion, Princeton: Princeton University Press.

Griswold, Charles L. 1999. Adam Smith and the virtues of enlightenment. Cambridge University Press. Groenewegen, P. D.

Haakonseen, Knud. 1996. Natural Law and Moral Philosophy: From Grotius to the Scottish Enlightenment, Cambridge University Press

Hont, I. and Ignatieff, M. 1993. Wealth and Virtue: The Shaping of Political Economy in the Scottish Enlightenment, Cambridge: Cambridge University Press.

Rothschild, Emma. 2001. Economic sentiments: Adam Smith, Condorcet and the Enlightenment. Harvard University Press.

Skinner, Quentin. 2002. Visions of Politics: Regarding Method, Cambridge: Cambridge University Press. Vivenza, Gloria. 2002. Adam Smith and the Classics, Oxford: Oxford University Press.

Winch, Donald. 1992. Adam Smith: Scottish moral philosopher as political economist. The Historical Journal, 35[01], 91-113. 